\title{
THE MATHEMATICS EDUCATION REFORM: WHY YOU SHOULD BE CONCERNED AND WHAT YOU CAN DO
}

\author{
H. WU
}

\section{To Chih-Han Sah, in memoriam}

\section{INTRODUCTION}

In 1962, when the New Math was still on its ascent, 75 leading mathematicians published an open letter in this Monthly to chide the New Math for its excesses [11]. It decried empty abstraction and rigid formalism, and made a strong case for learning the fundamentals of traditional mathematics: "elementary algebra, plane and solid geometry, trigonometry, analytic geometry and the calculus". It also affirmed the importance for students to be able

to use mathematical language with some fluency, ... to find proofs and, what may be the most important activity, to recognize a mathematical concept in, or to extract it from, a given concrete situation.

Unfortunately, this forceful statement is now all but forgotten in the mathematical research community.

Thirty-five years later, we are faced with another mathematics education reform. In the usual way in which this term is understood, it refers to both the K-12 mathematics education reform led by the National Council of Teachers of Mathematics (NCTM) and the calculus reform. This reform once again raises questions about the values of a mathematics education, this time not by imposing empty abstractions and rigid formalisms, but by redefining what constitutes mathematics and by advocating pedagogical practices based on opinions rather than research data of large-scale studies from cognitive psychology.

The reform has the potential to change completely the undergraduate mathematics curriculum and to throttle the normal process of producing a competent corps of scientists, engineers, and mathematicians. In some institutions, this potential is already a reality.

The purpose of this article is to discuss briefly some of the salient features of the reform, explain why the stakes are so high this time around, and finally point out some possible avenues for individual and collective action by mathematicians. Real progress in changing the direction of the reform will come only when reasoned arguments are heard from the whole mathematical community. 


\section{Some SPECIAL FEATURES OF THE REFORM}

The reform has its merits. For example, it has replaced some of the rotelearning in the traditional curriculum by supplying motivation and heuristic arguments. It has made students aware of the normal process of doing mathematics, such as making conjectures and looking for counter-examples. It has also made mathematics more relevant to the average student by promoting the use of realistic applications in the curriculum. This section is devoted to a few areas of concern in the reform in order to furnish a basis for discussion in the subsequent sections; see [24] and [25] for a more detailed discussion as well as a more complete list of references.

The main focus of this article is not on the reform as an abstract ideawho does not want to improve education?-but rather on its concrete manifestations in the classroom or its explicit statements concerning instructional issues. Education is not a theoretical construct, so the reform must be judged by its performance and not by its rhetoric.

The first area of concern is the cavalier manner in which the reform texts treat logical arguments; this may well be the most conspicuous deviation from previous educational practices. Whenever a justification for a mathematical statement is given in reform texts, it is not made clear as a rule whether it is a heuristic argument that is very far from a proof or even fallacious, or actually a valid proof. Bald assertions without justifications are also made without comment. At the same time, the reform prides itself on its vigorous promotion of "higher order thinking skills" and "mathematical reasoning" (e.g., [13, pp. 5-6], and [10, pp. 20-21]). This uneasy alliance between two inherently contradictory positions breeds many awkward situations. For example, a recent article [20] published in the official journal of the National Council of Teachers of Mathematics advocates teaching trigonometric identities such as $\sin 2 x=2 \sin x \cos x$ solely by graphing each side on the screen of a graphing calculator and observing that they coincide. There is no mention of a proof. Now if the authors had said that "in addition to proving the identity $\sin 2 x=2 \sin x \cos x$, using the graphing capability of a calculator can reinforce students' confidence in the abstract argument", we could have applauded them for making skillful use of technology in the service of mathematics.

Let us consider another example. On p. 208 of [7], the derivation of the quotient rule $(f / g)^{\prime}=\left(f^{\prime} g-f g^{\prime}\right) / g^{2}$ is given as follows: Let $Q=f / g$, then $f=Q g$. Differentiate both sides, employing the product rule for the right side, and solve for $Q^{\prime}$ to get the requisite formula. In this case, the formula is obtained by making use of the differentiability of $Q$, which is in fact part of what must be proved in the first place. Nevertheless, the circularity of this argument is allowed to stand in the face of prior assurances to the students that this is an "informal but mathematically sound justification" [7, p. ix], because the prevailing thinking is that this kind of intuitive argument is just 
right for most beginning math students. But what has happened to higher order thinking skills in the meantime?

One of the main goals of mathematics education enunciated in [11] was "to find proofs". In the current reform, this goal has been challenged, sometimes implicitly (e.g., [13, pp. 143-145], [16, p. 61]), and other times explicitly (e.g., [12]). In [12, p. 562], Mumford spoke for many reformers when he questioned why, in the context of calculus reform, we should even make a judicious and minimal presentation of proofs. Why "train them in making logical deductions" at all? His main argument is that "logical deduction has no place" in the practices of the sciences, nor in the lives of the rest of the educated public. While this point of view can be discussed on many levels, I shall follow [12] and simply stay within the context of calculus reform. Such an argument overlooks the fact that among the students in a typical calculus course are future math majors as well as serious users of mathematics. These two groups need rigorous mathematical training, and would not be satisfied with a steady diet of "persuasive heuristics", graphic displays, and nothing else. They comprise considerably more than one percent of the calculus student population as suggested in $[12, \mathrm{p}$. 563] (see, e.g., [24, p. 1536]). Unfortunately, most reform texts, notwithstanding the fact that they exclude these two groups by design, promote themselves as texts for all students. If they could explicitly make known this exclusion, then a good deal of the present concern about the reform would instantly disappear.

The argument of [12] also presupposes a severely utilitarian educational philosophy: if something is not useful, then throw it out of the curriculum. To a certain extent, even a liberal arts education makes some concessions to this philosophy. Recently, the Berkeley mathematics department voted to adopt as official text for "soft" calculus the applied version of [7], which is one of two books vigorously promoted in [12]. On the whole, though, most universities still manage to hold the line and endeavor to imbue students with the spirit of intellectual inquiry for its own sake. Students continue to be exposed, for example, to logical deductions in mathematics and poetic expressions in literature. Shakespeare has not yet been replaced entirely by Madison Avenue. There is something to be said about this time-honored tradition.

The same utilitarian impulse is responsible for a second major area of concern in the current reform, which is the over-emphasis on relevance and "real world applications". The need for applications in school mathematics curriculum is beyond debate, but are we willing to embrace a curriculum in which "the mathematics truly arises out of applications [and] the units are not centered around mathematical topics but rather application areas and themes, with the mathematical topics occurring as strands throughout the unit" [1]? The Interactive Mathematics Program (IMP) [8] comes close to realizing this rather extreme viewpoint, although all other reform texts succumb to its spell to varying degrees. 
Those who over-emphasize relevance in school mathematics appear to want to reclaim the attention of the sizable number of students who are turned off by mathematics, and to hone the working skills of prospective high school graduates in order to make them more employable in the hightech industry [5]. Now mathematics is a cohesive discipline with a well understood internal structure. A mathematics education ought to cultivate students' intellectual appreciation of this structure and cohesion. Reading the NCTM Standards [13]-[15], no one would believe that mathematics is getting its proper due in the present reform. To give a rather provocative example: a student coming out of a reform curriculum would not understand why the recent proof of Fermat's Last Theorem is a landmark event in human culture.

An application-oriented curriculum can furnish a valid mathematics education provided enough attention is give to mathematical closure. Tools developed for the purpose of solving a practical problem should be put in the proper mathematical context, and abstract ideas distilled from such solutions should preferably be applied to completely different situations to demonstrate the fundamental role of abstraction in mathematics. Unfortunately, mathematical closure is hardly ever applied in the reform. When the NCTM Standards discuss the problem of finding the roots of the cubic $5 x^{3}-12 x^{2}-16 x+8=0$ in the context of Grades 9-12 [13, pp. 152-3], the only expectation of the majority of the students is that they construct an algorithm for approximating the real roots and test it on a graphic calculator. This is all. No mention to this group of the nature of the roots of polynomials (are the real roots rational?), or the existence of real roots (if the degree is odd?), or the existence of complex roots in general, etc.

To put it in a musical context, an overly utilitarian approach to mathematics education is akin to impressing Beethoven's greatness on school students by presenting him solely as the composer of the tunes for the HuntleyBrinkley Show, the Beatles' movie Help!, and the recent TV ad for Acura. Even if we succeed, can we take pride in such a Pyrrhic victory?

A third area of concern in the current reform stems from the fact that mathematics is a precise technical language. Students must strive to master this new language. A tendency of the reform is to move mathematics completely back into the arena of everyday life where ambiguity and allusiveness thrive. A loss of precision in mathematical presentations is the result. One example is the way IMP [8] treats mathematical concepts. Consider the standard notion of the expected value of a random variable. In the IMP text, this concept is used throughout the second half of a unit called "The Game of Pig" [8, pp. 96-186], but it first appears in a homework problem as a term commonly used in everyday language [8, p. 134], and is subsequently never defined in the text proper. In the Glossary at the end of the whole book, it is stated: "Expected value: In a game or other probability situation, the average amount gained or lost per turn in the long run." [8, p. 257]. Without arguing whether such a definition is usable from a student's point of 
view (or whether it is even correct), I simply point out that in the Teacher's Guide for "The Game of Pig", teachers are alerted to the introduction of this new terminology, and that they are instructed to tell the students that "the concept of expected value is nothing new, ... [but] the use of such complex terminology makes it easier to state complex ideas". Whatever became of the goal to teach students to "extract a mathematical concept from a given situation"? Can this goal be accomplished if, instead of carefully guiding the students to perform the "extraction", the text systematically embeds the mathematics in the vagueness and uncertainty of everyday life?

Suppression of precision also takes the form of intentionally slighting basic algorithms and formulas. An example of the former is the various methods employed to avoid teaching even the basic multiplication and division algorithms in K-4. As example of the latter, the pre-calculus text [19] spends two pages (pp. 209-210) discussing the relationship between the measurements of an angle in degrees and radians, but assigns the discovery of the general formula relating the two to two exercises. Given this trend, we will soon see calculus texts which compute only derivatives of $x^{2}, x^{3}$, and $x^{4}$, but relegate the formula for $x^{n}$ to an exercise; better yet, they will compute $\int_{0}^{1} x^{5} d x$ and $\int_{5}^{6} \sin x d x$ but leave the statement and proof of the Fundamental Theorem of Calculus to an exercise. Where will this end?

The preceding concerns all have to do with curriculum, but there are others of a different nature. The foremost is the relative neglect in the K-12 reform of the issue of teacher qualification. A main cause of the dysfunctional mathematics classroom of the seventies and eighties, which eventually led to the call for reform in [18], is inadequate knowledge of mathematics. In light of this, the present emphasis of NCTM on curriculum, pedagogy, and assessment methods in [13]-[15], with no commitment to a rigorous program of re-training of the teachers in the field and a strengthening of the future teachers' mathematical education, practically guarantees the continued mediocrity (if not failure) of mathematics education in our nation [23].

Another concern is with the new pedagogy, which relies heavily on constructivistic instructional strategies, such as cooperative learning and the discovery method. As a theory of learning, constructivism holds that the acquisition of knowledge takes place only when the external input has been internalized and integrated into one's own mind. However, the current reform transforms constructivism into a theory of instruction ([10] \& [13]-[15]). In order to help along this mental construction, class time in reform classrooms is reserved primarily for students to re-discover or re-invent concepts and methods of solution. Furthermore, this process of re-discovery is facilitated by the use of cooperative learning. Having students work together in small cooperative groups is a preeminent characteristic of the present reform effort in school mathematics. In such a learning environment, the teacher ceases to be "the sage on the stage" and instead serves as "a guide on the side". 
While a little bit of group learning and guiding-on-the-side is good in the classroom, too much of this is happening in the reform classrooms to the detriment of good education. When cooperative learning rules, teachers cannot share their insights with students or warn them against pitfalls. Moreover, students cannot learn enthusiastically from their teacher in class and do the mental construction at home. Just how much substantive mathematics can be learned this way?

One would be quite mistaken to regard my critical comments on the pedagogical and instructional recommendations of the reform as nothing more than a mathematician's objection to facts well-established in cognitive psychology. It is a sobering experience to read the articles by Grossen [6] and Anderson-Reder-Simon [2], which provide critical assessments of these recommendations by an educator and three cognitive psychologists, respectively. In particular, the former points out the complexity in any successful application of cooperative learning and the lack of large-scale studies to support its unrestricted applications, while the latter takes to task many of the instructional prescriptions derived from constructivism.

\section{WHY IT MATTERS}

The most obvious reason why school mathematics education should matter to university professors is that a continuing influx of mathematically incompetent students would decimate the university mathematics curriculum. One can look no further than the United Kingdom to have one's worst fears confirmed. If a report released by the Council of the London Mathematical Society in October, 1995, is to be trusted, then the UK is some five years ahead of us in a mathematics education reform remarkably similar to our own in its rhetoric. If our reform takes hold, then according to [22], we can look forward to a generation of students with:

(i) a serious lack of essential technical facility - the ability to undertake numerical and algebraic calculation with fluency and accuracy;

(ii) a marked decline in analytic powers when faced with simple problems requiring more than one step;

(iii) a changed perception of what mathematics - in particular of the essential place within it of precision and proof.

But the worst is yet to come. For example, to the charge that the Harvard Calculus [7] passes students through calculus without requiring any algebraic skill, one reply was that students' symbolic manipulative skills are much weaker than they used to be, and so some symbolic manipulation should be eliminated from calculus. In the same vein, in response to the charge that students pass through reform calculus with at best a rudimentary knowledge of algebra, the comment from reformers was that we did this long before calculus reform. 
Instead of trying to uphold a certain standard and help mold as-yetunformed minds, educators simply accept deterioration in the classroom as a given. It would be only a small step to apply such a philosophy in earnest to demand a total revamping of undergraduate, and even graduate, mathematics programs in order to fit the deficiencies of the new generation. In point of fact, such suggestions have already been made. For example, [9] recommends that we "Change the first two years of collegiate mathematics to match the new K-12 curriculum." Not coincidentally, the opening statement of the Precalculus Project of the Calculus Bridge Consortium Based at Harvard University echoes this sentiment word for word: "Given the success of the reform calculus movement, students and teachers want reformed courses both preceding and following calculus" [4]. The mathematics department of a major state university started to revise all its upper divisional courses in May of 1996 in order to "mesh with the aftermath of the Harvard Calculus reform".

The logic of the reform is inexorable: once the reform is entrenched in $\mathrm{K}-12$, university mathematics courses will have to follow suit. The next step will be inevitably a demand for reform in the graduate program. Thus in no time at all, the burning question of the day will be whether or not proofs are allowed only in graduate courses.

We must object to the reform because it threatens to bring down the whole education system. Indeed, our students of today will be the teachers of tomorrow, so when university courses start to deteriorate our children will be taught by teachers who are mathematically worse-equipped than those of today. Then the next wave of students will perform even more poorly, and the poor performance will incite the educators to demand a second mathematics education reform. And the vicious circle will continue. Lest such worries be construed as sheer paranoia, let me quote a recent (1996) report from the organizer of a workshop for high school mathematics teachers in a Western state (who asked to remain anonymous):

In the afternoon we started talking about the state of students' preparation for calculus and all of them said it is getting worse year by year. ... The picture they painted for me was one in which [the teachers] are nearly powerless to prevent what they see as a watering down of the curriculum because administrators, untrained in mathematics, are making the decisions based on reports filled with what they describe as NCTM jargon. One teacher ... predicts that there will be no calculus course in three years because no one will be ready for it. 
The reform also raises a grave concern in a different context. The economic and social well-being of our nation is critically dependent on the existence of a robust corps of technicians in science and technology: the competent mathematicians, scientists, and engineers who evolve from school students gifted in science and mathematics. Because the reform favors weaker students, the top students end up being shortchanged, and the continuous supply of this technical corps is put in jeopardy. This problem is becoming so serious that it has alarmed the U.S. Department of Education. In a refreshingly straightforward document [17], it offers a criticism of the reform:

Ultimately, the drive to strengthen the education of students with outstanding talents is a drive toward excellence for all students. Education reform will be slowed if it is restricted to boosting standards for students at the bottom and middle rungs of the academic ladder. At the same time we raise the "floor" (the minimum levels of accomplishment we consider to be acceptable), we also must raise the "ceiling" (the highest academic level for which we strive).

\section{What MATHEMATiCiAnS CAN DO}

The open letter [11] is a remarkable document of sound educational principles in mathematics education, but it appears to be the only one that demonstrates the collective concern of the mathematical research community for school mathematics in the past half century. It has left almost no marks, because tangible results in education can be achieved only by sustained effort. The absence of such an effort by the mathematical community at large, especially the research community, has allowed the traditional K-12 curriculum and the teaching of calculus to deteriorate, thereby opening the floodgate to a multitude of educational ideas of dubious merit. The reform is the natural product of this indifference.

Professional mathematicians have an additional obligation to break this indifference and speak out against the defects of the reform, because teachers who wish to do so are under pressure to maintain a facade of compliance. As a teacher from Pennsylvania put it: "The 'other side' is making it very uncomfortable for teachers such as me, and we are dropping like flies. Whereas university professors like you can disagree with impunity, that same privilege is denied to those of us lower on the scale."

If we wish to shake off this indifference and enter into a discussion of mathematics education, then we have to enlarge our vision concerning the teaching of mathematics. We have to temporarily abandon the narrow focus of training future mathematicians and embrace the broader and more complicated issue of educating students who have diverse goals in life. We must also learn about the reality in schools where teachers are habitually overworked and have not the luxury of intellectual contemplation. Criticisms 
of the reform that do not take into account deviations from our normal "universe of discourse" are not likely to find a receptive audience.

In discussing the reform, we also have to be aware of the existence of the many serious defects in the generic traditional mathematics curriculum in the schools [24]. A return to "business as usual" would be no cure.

One last thing we need to be aware of is that, although our professional instincts compel us to insist on rigorously proving everything, there is no faster way to lose credibility as educators than to build our whole case against the reform on this one theme alone. It is far too easy, for example, to harp on the absence of $\epsilon-\delta$ proofs of the basic theorems of limit and continuity in the reform calculus texts, but a pedantic insistence on rigor is by no means the best approach to the teaching of elementary mathematics. It would be more realistic to ask that only the truly basic facts be proved in beginning courses and that there be careful differentiation between what is actually proved and what is not. Gaps can always be filled later, provided no circular reasoning is involved and provided the students are made aware of the gaps.

What then can we do, individually and collectively? Here are a few suggestions.

The situation regarding the calculus reform is relatively simple. Since it is being carried out mainly by our peers, we should press for a vigorous debate, not only in professional journals but also in every one of our own departments. If personal and anecdotal experiences serve, most mathematicians active in research regard the teaching of calculus as something unworthy of serious attention. The time to change this attitude is now before the reform gets out of control.

The K-12 reform is inherently more complicated and calls for efforts in more than one direction. First of all, NCTM is currently revising its Standards [13]-[15] for a second edition. It has created a Commission on the Future of the Standards and has asked several mathematics organizations, such as MAA, AMS, and SIAM, to create their own committees to work closely with the Commission over the next three years. These committees are to provide sustained advice and information. We should seek out members of these committees to give them our opinions on the reform in general and on the Standards in particular. This is our chance to infuse the Standards with more mathematical substance and a more balanced viewpoint.

In the meantime, we should offer our critical comments on the reform. In spite of pleas for the mathematical community to "speak with one voice" in support of the reform, we should keep up the fine critical tradition initiated in [11]. What is missing in the reform is the commitment to teach mathematics, in all its guises, without violating its integrity. If we mathematicians do not reaffirm this commitment, then who will?

Something much less easy to achieve but immensely more important is for mathematicicans to help improve the training of prospective school teachers. Mathematics education on the college level is, more often than not, 
aimed exclusively at producing future mathematicians. The usual college mathematics courses drill the students on the technical details of fundamentals in order to prepare them for graduate work in mathematics. But for those who leave mathematics after their college degree, e.g., school teachers, such courses yield brief glimpses of the trees but never the panorama of the forest. In the words of Allyn Jackson, such an experience in mathematics is akin to "finishing a BA in English literature having done a lot of technical analysis of Shakespeare but having no idea about Shakespeare's stature in English literature". Because less than $20 \%$ of math majors go on to do graduate work, we are addressing only $20 \%$ of our students while pretending to be teaching them all; see [3] and [23]. A narrow focus on producing future mathematicians is a significant factor in the inadequate mathematical preparation of our school teachers.

There is no simple remedy for this educational difficulty. Larger institutions can schedule different sections of the same course to satisfy the divergent needs of the students. Smaller colleges can overcome this obstacle only by the extra dedication and ingenuity of instructors. We are all capable of making a contribution to this important matter just by being more conscientious in carrying out our normal duties.

A third area for possible action is direct participation. For example:

(A) Be an author of school mathematics texts.

(B) Join a group that engages in curricular activities.

(C) Act as consultant and critic on education.

(D) Work directly with one's own local school board or teachers.

(E) Speak up as a citizen and do grassroots work.

Regarding (B), the main difficulty is an almost unbridgeable chasm between educators in the K-12 reform and mathematicians, so any contribution we hope to make here requires establishing some mutual trust between the two groups. Regarding (C), despite exhortations by NSF and AMS for research mathematicians to partake of the education enterprise, there is in fact no support for critical educational writing. On the other hand, NSF funded the writing of textbooks such as Earth Algebra [21]. Life is indeed full of mysteries.

Thus far, the most effective method of making one's voice heard in K12 education is by way of grassroots efforts. Prime examples of this are the various groups organized by parents in California, which played a substantial role in hastening the revision of the 1992 California Mathematics Framework [10]. These and other action groups serve the vital function of giving voice to alternative points of view and galvanizing dissent into action. If we can add our professional voices to the efforts of these groups, we can help create a potent force for change within education.

Acknowledgement: In writing this article, I have received invaluable help from Richard Askey, Steven Krantz, and Henrietta Wallace. The corrections 
of Madge Goldman and Ralph Raimi in a preliminary version led to vast improvements in style and exposition. The suggestions of Henry Alder, Al Cuoco, Richard Escobales, Carol Gambill, Deborah Tepper Haimo, Motohico Mulase, Han Sah, John Schommer, Dick Stanley, and Lynn Steen were also very important. It gives me pleasure to thank them all.

\section{REFERENCES}

[1] ARISE, Information material available (1993) from COMAP, Inc., Suite \#210, 57 Bedford Street, Lexington, MA 02173.

[2] J. R. Anderson, L. M. Reder and H. A. Simon, Applications and misapplications of cognitive psychology to mathematics education, available at http://sands.psy.cmu.edu/personal/ja/misapplied.html

[3] R. C. Atkinson and D. Tuzin, Equilibrium in the research university, Change, May/June 1992, 20-31.

[4] The Precalculus Project of the Calculus Bridge Consortium Based at Harvard University, available at http://www.math.harvard.edu/ calculus/Precalc/Description.html

[5] S. L. Forman and L. A. Steen, Mathematics for work, Bulletin of the International Commission on Mathematical Instruction (ICMI), No. 37, Dec. 1994, 17-22.

[6] Bonnie Grossen, Making research serve the profession, American Educator, Fall 1996, pp. 7-8, 22-27.

[7] D. Hughes-Hallet et al., Calculus, Wiley, New York, 1994.

[8] Interactive Mathematics Program, Year 1, Key Curriculum Press, Berkeley, CA, 1997.

[9] J. J. Kaput, Long-term algebra reform: democratizing access to big ideas, in The Algebra Initiative Colloquium, Volume I, C. B. Lacampagne, ed., U.S. Department of Education, Washington D.C., 1995, 33-49.

[10] Mathematics Framework for California Public Schools, California Department of Education, Sacramento, CA, 1992.

[11] On the mathematical curriculum of the high school, Amer. Math. Monthly 69 (1962), 189-193.

[12] D. Mumford, Calulus reform-For the millions, Notices Amer. Math. Soc. 44 (1997), $559-563$.

[13] Curriculum and Evaluation Standards for School Mathematics, National Council of Teachers of Mathematics, Reston, 1989. Available at http://www.enc.org/online/NCTM/280dtoc1.html

[14] Professional Standards for Teaching Mathematics, National Council of Teachers of Mathematics, Reston, 1991.

[15] Assessment Standards for School Mathematics, National Council of Teachers of Mathematics, Reston, 1995.

[16] Geometry from Multiple Perspectives, Curriculum and Evaluation Standards for School Mathematics Addenda Series, National Council of Teachers of Mathematics, Reston, 1991.

[17] National Excellence: A Case For Developing America's Talent, U.S. Department of Education, Washington D.C., October 1993.

[18] A Nation at Risk, U.S. Department of Education, Washington D.C., 1983.

[19] The North Carolina School of Science and Mathematics, Contemporary Precalculus Through Applications, Janson Publications, Dedham, 1992.

[20] J. Pelech and J. Parker, The graphing calculator and division of fractions, Math. Teacher 89 (1996), 304-305.

[21] C. Schaufele and N. Zumoff, Earth Algebra, Preliminary Edition, HarperCollins, 1993.

[22] Tackling the Mathematical Problem, A report to the London Mathematical Society, Institute of Mathematics and its Applications, and the Royal Statistical Society, October 1995. Available at http://www.qmw.ac.uk/ lms/tackling/report.html

[23] $\mathrm{H}$. Wu, On the education of math majors, in Issues in Contemporary Mathematics Instruction, edited by E. Gavosto, S. G. Krantz, and W. G. McCallum, Cambridge University Press, 1998. 
[24] H. Wu, The mathematician and the mathematics education reform, Notices Amer. Math. Society 43 (1996), 1531-1537.

[25] H. Wu, The mathematics education reform: what is it and why should you care? Available from the author or at http://math.berkeley.edu/ wu

Department of Mathematics \#3840

University of CALIFornia

BERKELEY CA 94720-3840

wu@math.berkeley.edu 